\title{
Strategies for Preventing and Resolving Temporary Fossilization in Second Language Acquisition
}

\author{
Manqiu Qian \& Zhihong Xiao \\ School of Foreign Languages, Changsha Medical University \\ Leifeng Road, Yuelu District, Changsha, Hunan 410219, China \\ Tel: 86-731-8849-8048Ｅ-mail: qianlaoshi0822@126.com
}

The research is financed by the fund of Higher Colleges and Universities of Hunan Province, China. (Project No.09321402)

\begin{abstract}
Based on the practice of college English teaching and learning in China, the paper reviews the phenomenon and causes of the temporary fossilization in second language acquisition and offers some corresponding strategies for preventing and surmounting the obstacles in the hope of promoting the reactivation of the next climax.
\end{abstract}

Keywords: Second language acquisition, Temporary fossilization, Strategies

\section{Introduction}

In the early period of implementation of the policy of opening China to the outside world when many English teachers of China paid great attention to the puzzling phenomenon: "New Concept English" and "English 900"enjoyed great popularity in China and they were used as the textbook in many English training institutions. They used to be broadcast constantly by TV and radio stations and many parents regarded seeing movies and imitating tapes as an important way for guiding children in their English learning. For a time, the two prevailing books evoked people's desire for English knowledge. However, in retrospect, people found that only few had a good mastery of English in the wake of having finished learning them. Why? As college English teachers, the authors attempt to make a preliminary probe into the causes for the above phenomenon from psycholinguistic aspects, of which, we believe that temporary fossilization is the greatest obstacle in second language acquisition, and to take corresponding measures positively is a good way for us to prevent and resolve temporary fossilization so as to raise the efficiency of our English teaching work.

Fossilization Selinker (1970) noted that most L2 learners fail to reach target language competence. That is, they stop learning when their internalized rule system contains rules different from those of the target language. This is referred to as 'fossilization'.

Intelanguage Interlanguage is the term coined by Selinker (1972) to refer to the systematic knowledge of a second language which is independent of both the learner's first language and the target language. The term has come to be used with different but related meanings: (1) to refer to the series of interlocking systems which characterize acquisition, (2) to refer to the system that is observed at a single stage of development (i.e. ' an interlanguage'), and (3) to refer to particular mother tongue/target language combination (e.g. French mother tongue/English target language vs German mother tongue/English target language).

Temporary fossilization It refers to the stagnant process in which non-target factors are fixed in the target language to a certain stage. Research shows only $5 \%$ can reach the target language while $95 \%$ can't. This kind of phenomenon is called temporary interlanguage fossilization.

\section{Causes of temporary fossilization}

The research of the emergence, developmental process analysis and interlanguage fossilization shows that foreign language learning is a kind of skill learning in essence. However, "plateau phenomenon" is the common phenomenon and the rule of skill learning, that is, the initial learning ability of learners draws in a linear increase, and to a certain stage, it will be in stagnant, then the ability curve shows flatly or even in decline. This plateau phenomenon can be found in interlanguage developmental process of Chinese learners. The learners will reach another peak after receiving an optimal input and their linguistic ability will realize a second leap, such as living and learning in the English-speaking countries. Analyses on the temporality of interlanguage fossilization help to overcome those obstacles. Many scholars analyzed the cause of fossilization and separated fossilization into personal and general factors.

Personal factors such as those identified by Schumann and Schumann are difficult to observe by a third person. This methodological problem has been solved by two ways. First one is to use of diary studies. The second solution to the 
methodological problem is to use questionnaires and interviews with individual learners. Personal factors are by definition heterogeneous, it can be grouped together as: (1) Group dynamics, group dynamics seem to be important in classroom SLA. Bailey (1983) records in some detail the anxiety and competitiveness experienced by a number of diarists. Some classroom learners make overt comparisons of themselves with other learners. In another kind of comparison, learners math how they think they are progressing against their expectations. Often these comparisons result in emotive responses to the language-learning experience. Competitiveness may be manifested in a desire to out-do other language learners by shouting out answers in class, or by racing through examinations to be the first to finish. However, once group dynamics transfers at the negative direction, students will feel anxious and shameful.

(2) Attitudes to the teacher and course materials, students will inevitably have very different views about the kind of teacher they think is best for them. Some prefer a teacher who, in Stevick's (1980)

Term, creates 'space' for them to pursue their own learning paths. Others prefer a teacher who structures the learning tasks much more tightly. Learns also vary in their attitudes to teaching materials. In general, adult learners dislike having a course book imposed upon them in a rigid way. They prefer a variety of materials and the opportunity to use them in ways they choose for themselves.

(3) Individual learning techniques, there is tremendous variety in the techniques employed by different learners.

\section{General factors which they consider are}

(1) Age, success in SLA also appears to be strongly related to the age when SLA is commenced. This is particularly the case where pronunciation is concerned.

(2) Intelligence and aptitude, learning a L2 in a classroom involves two sets of intellectual abilities, it involves what might be called 'a general academic or reasoning ability (Stern 1983:386'), often referred to as intelligence. This ability is involved in the learning of other school subjects as well as a L2; the other kind of ability consists of specific cognitive qualities needed for SLA, often referred to as aptitude.

(3) Cognitive style, cognitive style is a term used to refer to the manner in which people perceive, conceptualize, organize, and recall information. Each person is considered to have a more or less consistent mode of cognitive functioning.

(4) Attitudes and motivation, Schumann (1978) lists 'attitude' as a social factor on a par with variables such as 'size of learning group', and 'motivation' as an affective factor alongside 'culture shock'. Gardner and Lambert (1972) define 'motivation' in terms of the L2 learner's overall goal or orientation, and 'attitude' as the persistence shown by the learner in striving for a goal. Brown also distinguishes 'motivation' and 'attitudes'. He identifies three types of motivation: a), global motivation, which consists of a general orientation to the goal of learning a L2; b), situational motivation, which varies according to the situation in which learning takes place(the motivation associated with classroom learning is distinct from the motivation involved in naturalistic learning); c), task motivation, which is the motivation for performing particular learning tasks.

(5) Personality, one of the intuitively appealing hypotheses that has been investigated is that extroverted learners learn more rapidly and are more successful than introverted learns. It has been suggested that extroverted learns will find it easier to make contact with other users of the L2 and therefore will obtain more input.

In the process of second language leaning, all the factors listed above are likely to hold back the improvement of second language level to a degree. As an English teacher, out final purpose is not to find out the causes but to research the efficient measures to guide learners to develop towards in a positive direction.

\section{Some strategies to overcome temporary fossilization}

\subsection{Taking a right attitude to students' mistakes}

By research on interlanguage, People realized that making mistakes is not a sign of failure, but it is an inevitable phenomenon and teachers should "respect" students' errors, because it is a process that reaches the target language. Respecting errors does not mean taking no notice of them, but it does mean that they should not be treated as necessarily being evidence of stupidity, idleness or evil intent on the part of the learner. For example, when the foreign teachers correct the pronunciation, it is because there is no "equal" English phoneme in Chinese that they failed again and again. The teachers might blame the students for their failure, saying "why you always pronounce it wrong" impatiently, which may result in hurting their confidence, in many cases, some students may even give up efforts to reach the target pronunciation. To others, the wrong pronunciations will be reserved in the interlanguage. Instead, the teachers should take a developmental attitude to students' errors and mistakes, blame them less and encourage them more. This helps students to work on mentality of being afraid of making mistakes. Understanding that not only helps learners to overcome the psychological fear of mistakes, enhance the self-confidence to learn a foreign language, but also helps teachers take a correct attitude toward students' mistakes, facilitate them to analyze these mistakes and 
develop corresponding teaching approaches and teaching tasks so as to correct errors, reduce errors, thereby reducing the occurrence of fossilization.

\section{2 stimulating the students' motivation to learn a foreign language}

The English majors can reach the communicative purpose after one or two year's systematic learning with a certain degree of communicative skill and strategies. At this time, on one hand, the teachers should stimulate their motivation by different kinds of methods, make them not content with their present level and continue to learn about target language actively. In this way, students' interlanguage is stimulated by motivation and continued to get closer to target language. On the other hand, teachers should consider of difficulty of the task, intensity and challenging to the learners as well as independent learning and the ability of making judgments to ensure that students can complete the tasks and remain a certain degree of interest but not anti-climax.

\subsection{Paying attentions to verbal output and grasping the relationship between accuracy and fluency}

The development of interlanguage requires both optimal input and output, systematic ability can be developed and assumption can be tested through output, so as to make the language into automatic mechanism, thus promoting the development of interlanguage. Generally speaking, the English majors practice more writing output than verbal output, therefore, attention should be paid to the learner's oral output. In training student's oral ability, teachers should grasp the relationship between accuracy and fluency. Guided by communicative teaching approach, many teachers used to focus on the fluency and ignore the errors and accuracy. Practice shows that in premature pursuit of fluency is harmful to the development of language of learners. Between the two, the accuracy should in be the first place. In oral teaching activities, teachers should guide students to focus on language accuracy, requiring students to express meaning in the form of monitoring and encourage them to correct or amend once they are aware of errors.

\subsection{Giving strategic feedback}

Carefully designed feedback can prevent the formation of fossilization effectively. Teachers should provide timely feedback after learners complete a learning task. According to interactive feedback of Vigil and Oller, the best one is the combination of positive emotional feedback and negative cognitive feedback. The former encourages and stimulates students to continue to learn while the latter tells learners to make some changes and modifications.

\subsection{Stimulating students' imagination and paying attention to their creativity.}

In human brain's cognitive structure, each student has developed a set of cognitive schemata, teachers can help students to restructuring these known schema. In other words, teachers stimulate students to develop a special ability of using the known schema to express unknown meaning, which can train their creative thinking and divergent thinking.

\subsection{Encouraging learns to become a good language learner from the following aspects}

1) Being able to respond to the group dynamics of the learning situations so as not develop negative anxiety and inhibitions;

2) Seeking out all opportunities to use and practice the target language;

3) Making maximum use of the opportunities afforded to practice listening to and responding to speech in the L2 addressed to him and to others-----this will involve attending to meaning rather than to form;

4) Supplementing the learning that derives from direct contact with speakers of the L2 with learning derived from the use of study techniques (such as making vocabulary lists)----this is likely to involve attention to form;

5) Being an adolescent or an adult rather than a young child, at least as far as the early stages of grammatical development are concerned;

6) Possessing sufficient analytic skills to perceive, categorize, and store the linguistic features of the L2 and also to monitor errors;

7) Possessing a strong reason for learning the L2 (which may reflect an integrative or an instrumental motivation) and also develop a strong 'task motivation'(i.e. respond positively to the learning taskes chosen or provided);

8) Being prepared to experiment by taking risks, even if this makes the learner appear foolish;

9) Being capable of adapting to different learning conditions.

\section{Conclusion}

At present, the waves of college English reform go ahead with full stream. Especially under the guidance of the National College English Curriculum Requirements, we have made the great changes in the terms of teaching approaches, learning style and effectiveness. But the reasons for the long-standing problem of "time-consuming and inefficient" needed to be excavated fundamentally and the advisable countermeasures should be found out. The author believes that the second language learner constitutes the main aspect of the contradiction; psychological factors are the 
obstacles blocking the road to progress. The author and some colleagues are exploring the temporary fossilization, simultaneously, we are conduct empirical research in teaching practice for the purpose of bring the teachers' leading role into full play and helping students to prevent and overcome fossilized stage, and in the hope that our initial trial can arise resonance with common friends.

\section{References}

Ellis, R. (1999). Understanding Second Language Acquisition Shanghai Foreign Language education press.

Ellis, R. (1994). The Study of Second Language Acquisition. Oxford: Oxford University Press.

Selinker, L. (199-231). Interlanguage. IRAL, 1972, (10).

Selinker, L. (1992). Rediscovering Interlanguage London: Longman.

Selinker, L. (1996). Fossilization: What We Think We Know. Internet.

Adams, M. 1978a. 'Methodology for examining second language acquisition' in Hatch (ed.).

Adjemian, C. 1976. 'On the nature of interlanguage systems. ’ Language Learning 26: 297-320.

Allwright, R.1975. 'problems in the study of the language teacher's treatment of learner error' in M. Burt and H. Dualy. (eds.). On TESOL 1975.Washington D.C.: TESOL.

Gass,S. and L. Selinker. (eds.). 1983. Language Transfer in Language Learning. Rowley, Mass.: Newbury House.

R.Garder and W. Lambert. (Newburry House,1972) Attitudes and Motivation in Second Language Acquisition. 